تأثير برنامج تدريبى بإستخدام المحاكاة بتغيير الهدف على تحسين زمن الاستجابة الحركية المركبة

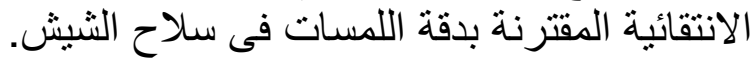

محمد عبد العزيز إبراهيم

قسم نظريات ونطبيقات المناز لات والرياضات الفردية بكلية التربية الرياضية للبنين جامعة الزقازيق - جمهورية مصر العربية.

المقدمة واهمبة البحث

إن التدريب الرياضي بصوره المتعددة يعد الوسيلة الأساسية التي تعمل علي تلبية متطلبات النشـاط الرياضـي وتطويره

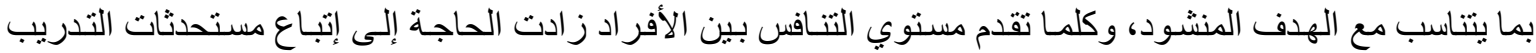
للارتقاء بهذه المستويات.

وتعد سرعة الاستجابة الحركية من الصفات البدنية الضرورية لأي نشاط رياضي ولكن تختلف درجة أهميتها من نشـاط

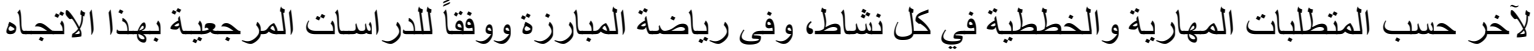

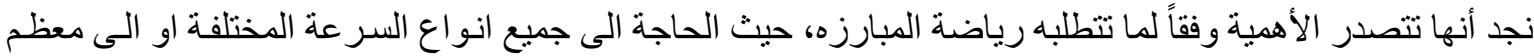

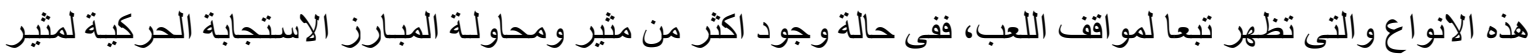

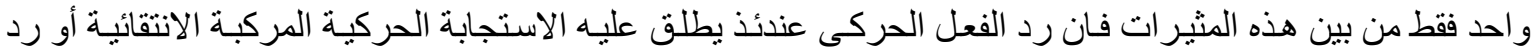
الفعل الحركى التمبيزى (المركب) وهذا النوع هود النون السائد فى المبارزه.

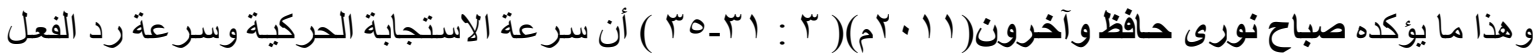

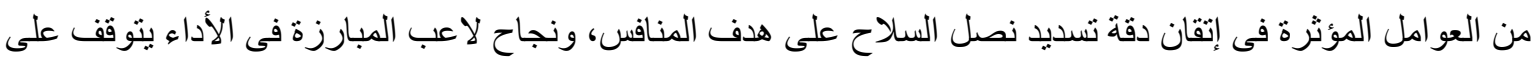

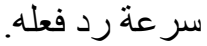

وفى رياضة المبارزة يجب أن يمتلك المبارز الذى هو فى وضعية الهجوم الى سرعة استجابة حركية بشكل مميز وذللك

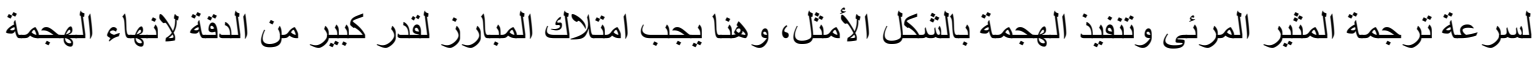

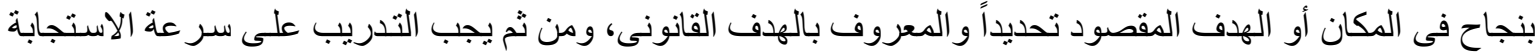
الحركية المركبة الانتقائية المقترنة بدقة الأداء.

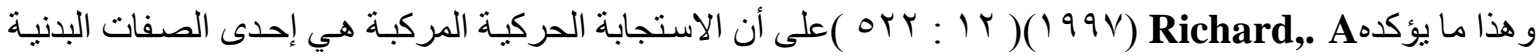

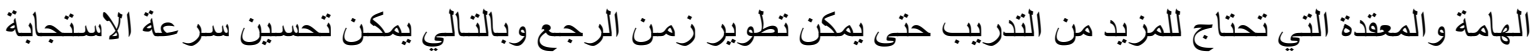

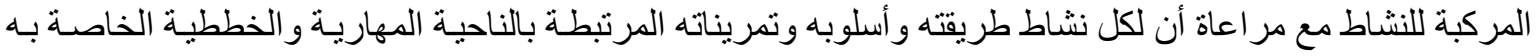

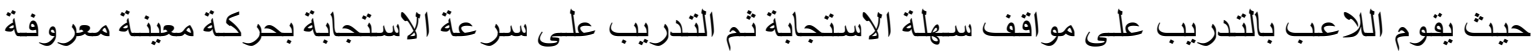

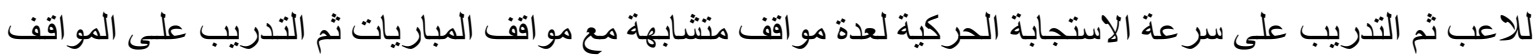
الحقيقة التي تحدث في المنافسات.

وحديثاً فان الصورة الحقيقية لتطبيق الهندسـة الرياضية و التي بواسطتها يتمكن المدرب من التدريب و التقويم المباشـر

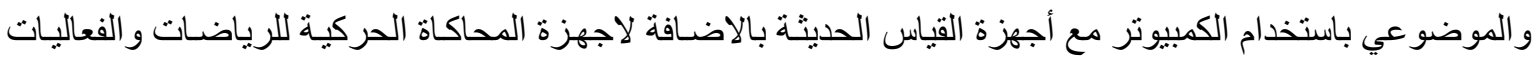

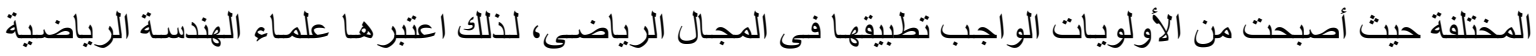

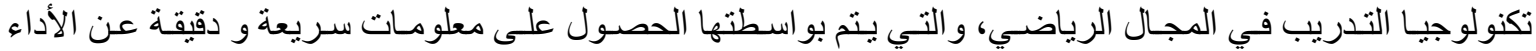

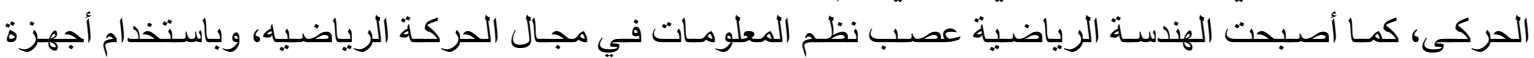

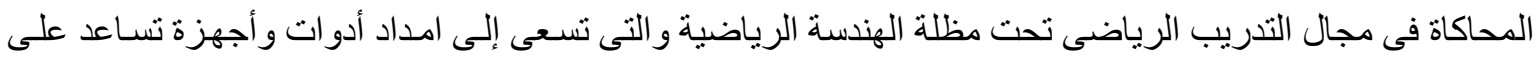
سهولة توصيل المعلومات الى المتدرب، وتسعى الى ربط التدريب بالحواس. 
ولقد لاحظ الباحث ومن خـلال المستح المرجعي للار اسـات المرتبطة أنـة نوجد مجمو عـة من الدر اسـات في حدود علم

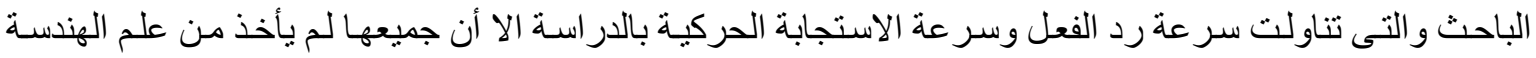

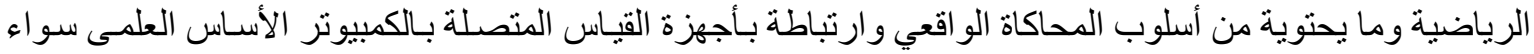

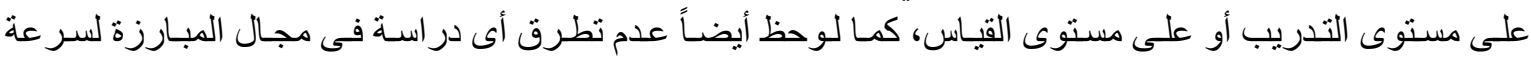

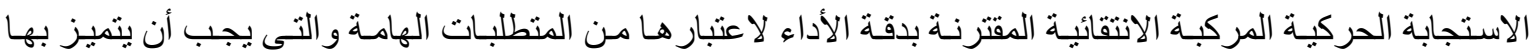

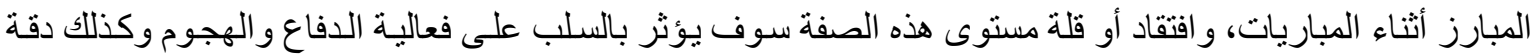

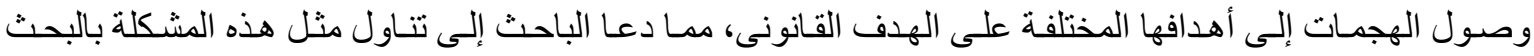

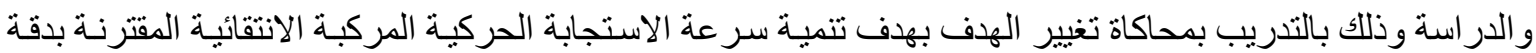
الأداء في رياضة المبارزة. هدف البحث:

يهدف البحث الى التعرف على تأثنير برنـامج تدريبى بإستخدام المحاكاة بتغيير الهدف على تحسين زمن الاستجابة

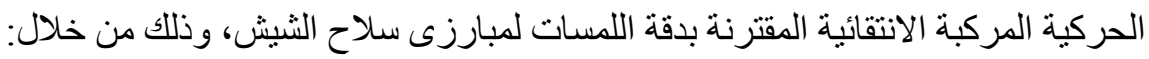
ا ـ تصميم برنامج تدريبى بإستخدام محاكاة تغيير الهدف. r. تأثثير البرنـامج التدريبى بإستخدام محاكاة تغيير الهدف على تحسين زمـن الاستجابة الحركيـة المركبـة الانتقائيـة

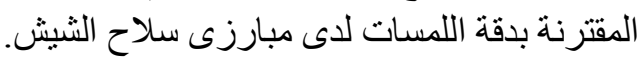
ب. در اسة الفروق بين القياسين القبلى و البعدى فى زمن الاستجابة الحركية المركبة الانتقائية المقترنة بدقة اللمسات لدى

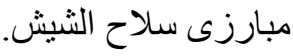
ع. العلاقة الارتباطية بين زمن الاستجابة الحركية المركبة الانتقائية ودقة اللمسات لدى مبارزى سلاح الثيش. فروض البحث: ا ـ توجد فروق دالة احصـائياً بين القياسين القبلى و البعدى فى زمن الاستجابة الحركية المركبة الانتقائية للمجموعة التجريبية لصالح القياس البعدى. ץ. توجد فروق داله احصائياً بين القياسين القبلى والبعدى فى دقة اللمسات للمجموعة التجريبية لصالح القياس البعدى.

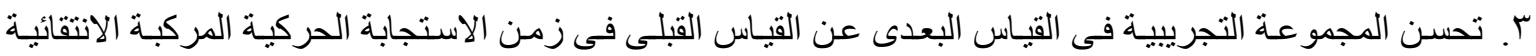
المقترن بدقة اللمسات. ع. توجد علاقة ارتباطية داله بين متغير ات زمن الاستجابة الحركية المركبة الانتقائية ودقة اللمسات.

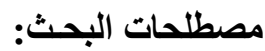

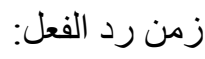
" الفترة الزمنية المستغرقة بين حدوث المثير وبين بداية الاستجابة". ( ( 1 ( ) ) رد الفعل المركب:

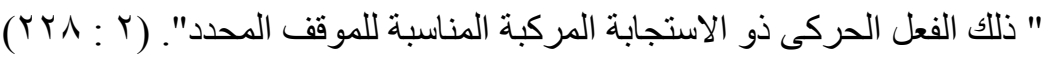




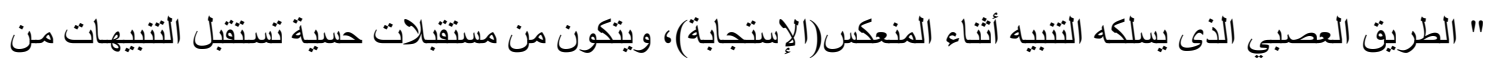

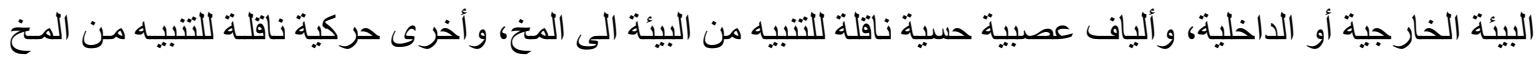

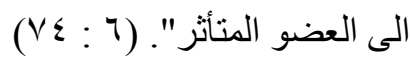
الاستجابة المركبة الانتقائية:

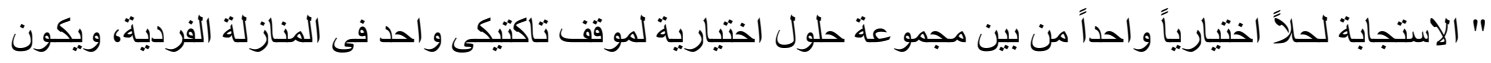

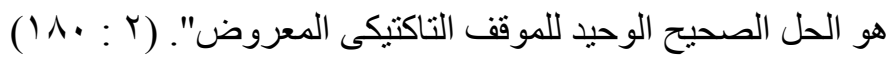
المستقبلات العصبية_العضلية: " مستقبلات تقوم بتحويل طاقة المثير الخارجى الى طاقة خاصة على شكل اثـارة عصبية لنقل المعلومـات الى المر اكز

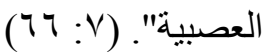

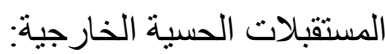

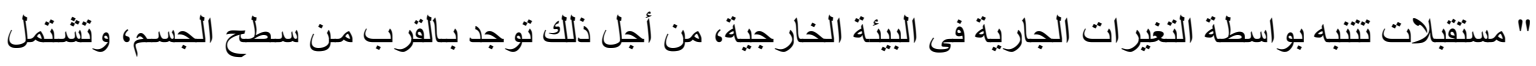

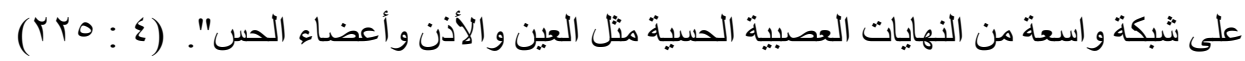
أسلوب التدريب بالمحاكاة: " المحاكاة هي أسلوب تدريبي يقوم فيه المدرب بتهيئة بيئة تدريبية للمتدربين نشبه البيئة الحقيقية لموضوع التدريب".

الدراسـات المرجعية:

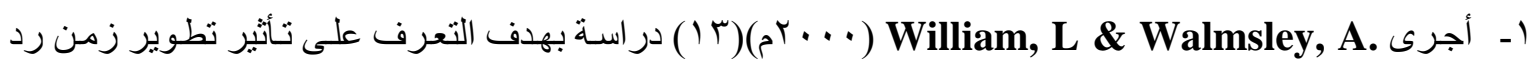

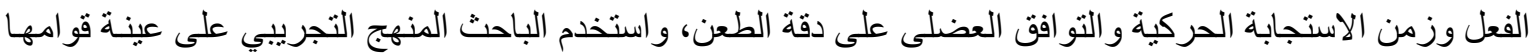

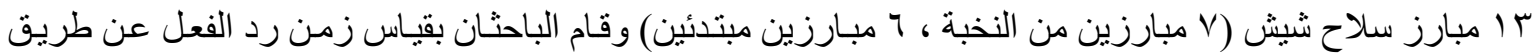

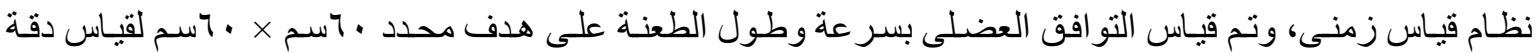

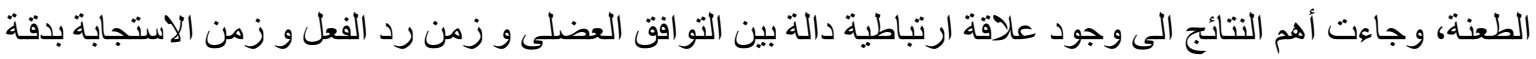
اللمسات.

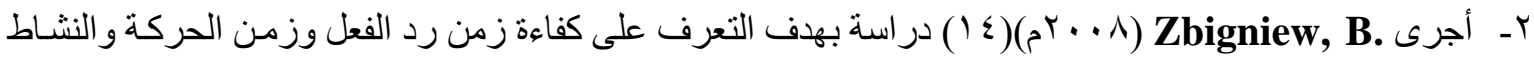

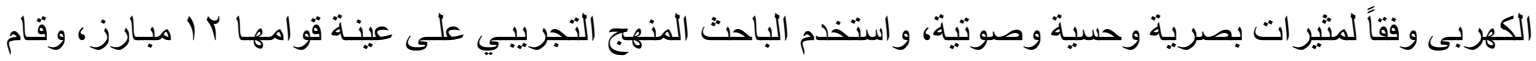

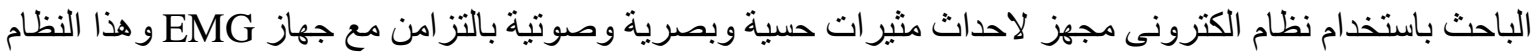

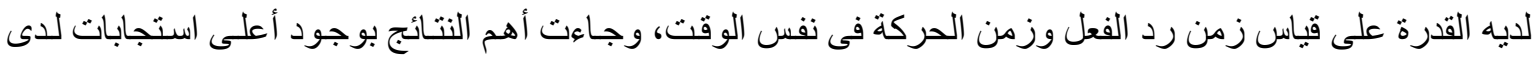

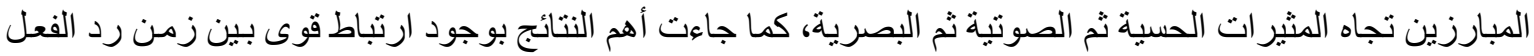

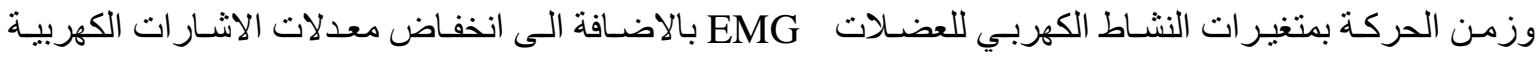
للعضلات أثناء الاستجابة للمثير ات الثناتثة.

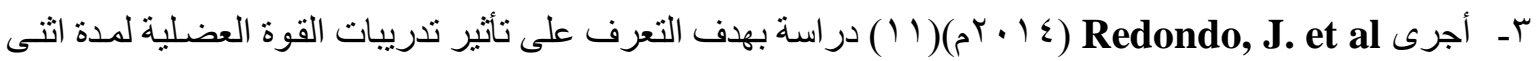

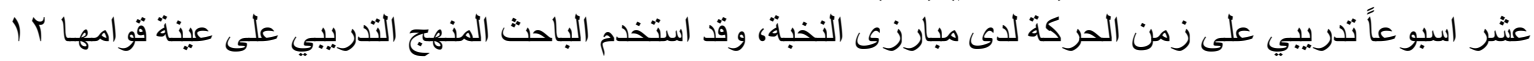

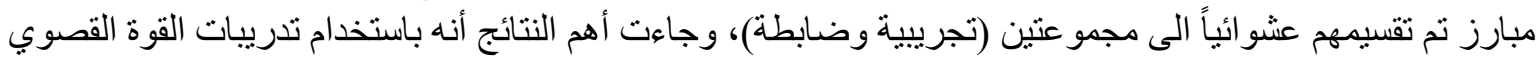

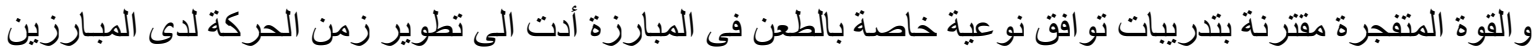


بصورة ملحوظة مقارنة باستخدام هذه التدرييات بصورة منفردة عن تدريبات التو افق.

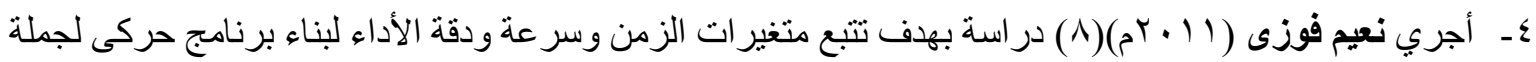

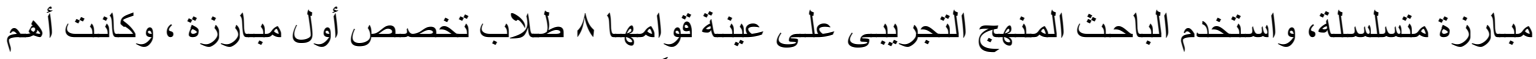

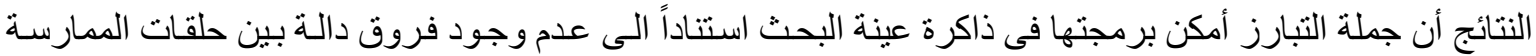

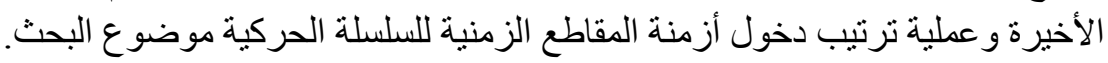
إجراعات البحث:

منهج البحث: استخدم الباحث المنهج التجريبى لمجمو عة واحدة بإجر اء القياسين القبلى و البعدى لمناسبته لنوع وطبيعة هذا البحث. مجتمع و عينـة البحث:

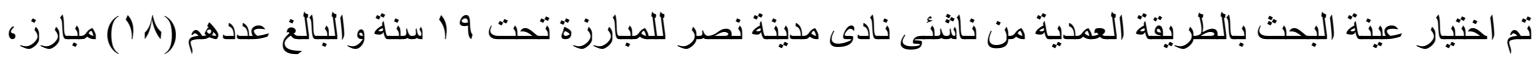
وقام الباحث باختيار عدد (T) مبارزين كعينة استطلاعية وبذلك أصبح عدد أفر اد عينة البحث الأساسية (ب ا ( ) مبارز. شروط اختيار عينـة البحث: تم اختبار عينة البحث وفقاً للشروط التالية: ا ـ ألا يقل العمر التدريبى عن ست سنوات. rـ اجادة مهار ات المبارزه بسلاح الثيش و أدائها بالتكنيك السليم. rـ الانتظام فى التدريب و عدم الانقطاع حتى وقت تطبيق التجربة. ع - خلو أفر اد العينة من الاصـابات. هـ حصولهم على المر اكز الاولى فى بعض البطو لات المحلية والدولية. 7- مسجلون بالاتحاد المصرى للمبارزة.

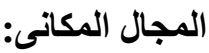

تم تطبيق البرنامج التدريبى وكذلك اجر اء القياسـات الخاصـة باختبار ات زمن سـرعة الاستجابة الحركيـة وزمن رد الفعل المركب المقترن بدقة اللمسات بنادى مدينة نصر المرئ

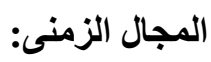

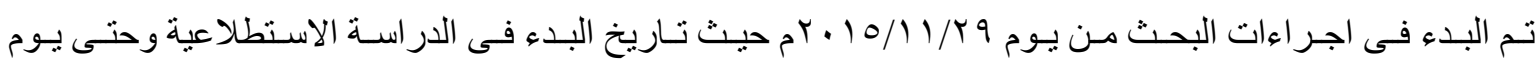

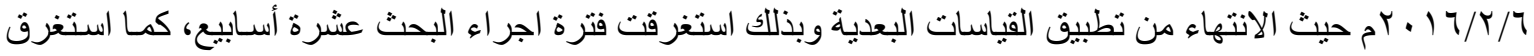

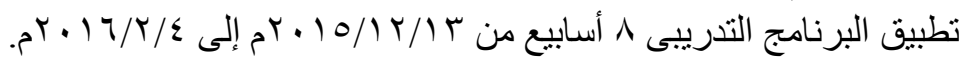
تجانس عينة البحث:

تم إجر اء التجانس لجميع أفر اد عينة البحث في متغير ات معدلات النمو والعمر التدريبى، واختبار ات زمن الاستجابة

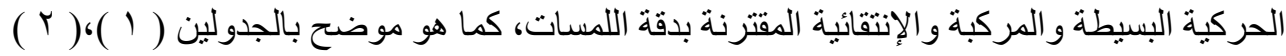




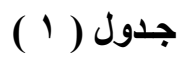

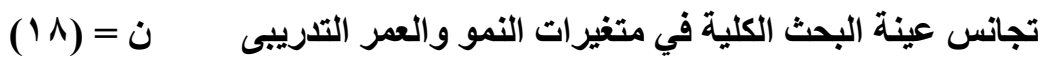

\begin{tabular}{|c|c|c|c|c|c|}
\hline الالتواء & الوسيط & الانحراف & المتوسطي الحسبي & وحدة القياس & المتغيرات \\
\hline $1.07-$ & 11 &..$\varepsilon r$ & IV.V^ & سنة & السن \\
\hline $1 . r 0-$ & $1 V \varepsilon$ & $0 . \leqslant r$ & 181.07 & سنتيمتر & أرتفاع القامة \\
\hline $1.15=$ & $v \cdot$ & 9.91 & 71.9. & كيلو جرام & الوزن \\
\hline..$\varepsilon \varepsilon$ & 7 & .07 & 7.11 & سنة & العمر التدريبي \\
\hline
\end{tabular}

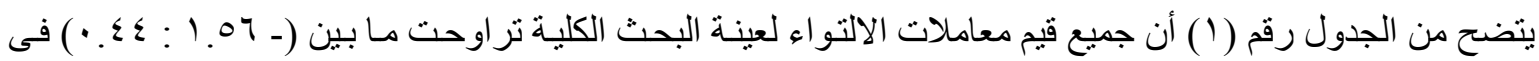

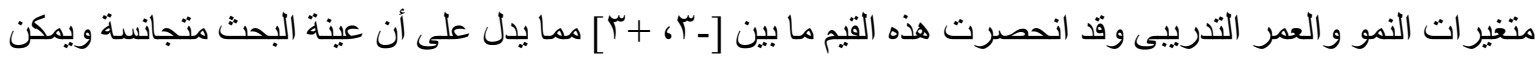
أن تكون نتائجها ممثله للمجتمع تمثيلاً اعتدالياً.

\section{جدول (r)}

تجانس عينة البحث الكلية في اختبارات زمن الاستجابة الحركية البسيطة والمركبة

والإنتقائية المقترنة بلةقة اللمسات ن = (1 )

\begin{tabular}{|c|c|c|c|c|c|c|}
\hline الالتواء & الوسيط & الالاحعراف & الحستوسط & والقياس & \multicolumn{2}{|c|}{ الاختبارات } \\
\hline $1.9-$ & $r \cdots .0$. & $9 . \Gamma \leq$ & $19 v .11$ & مللى ثانية & زمن رد الفعل & \multirow{3}{*}{ الحركية على هدف الاستجابة } \\
\hline$\cdot . \leqslant V-$ & oro.o. & $\varepsilon .94$ & Or\&.VY & مللى ثانية & زمن الحركة & \\
\hline$\because 7-$ & VYr & $\Lambda . \leqslant V$ & VrI.Ar & مللى ثانية & زمن الاستجابة الحركية & \\
\hline$\because \bullet \varepsilon$ & Y19.0. & $1 Y .00$ & r19.7V & مللى ثانية & زمن رد الفعل & \multirow{3}{*}{ الحركية لعدة استجابات الاستجابة } \\
\hline $1 . .0$ & oqr... & v.q1 & $090 . \vee \wedge$ & مللى ثانية & زمن الحركة & \\
\hline $.19-$ & Alr.o. & 17.78 & Alr. & مللى ثانية & زمن الاستجابة الحركية & \\
\hline$\because .00$ & YI & $11 . V Y$ & Y18.1V & مللى ثانية & زمن رد الفعل & \multirow{4}{*}{ الإنتقائية و المقية المركبة الاستجة المبة المبة } \\
\hline$\because \cdot r-$ & 099 & $11 . \wedge \varepsilon$ & $0 ৭ \wedge . \wedge q$ & مللى ثانية & زمن الحركة & \\
\hline $1.11-$ & Arr & $r \cdot . r^{\circ}$ & 110.9 & مللى ثانية & زمن الاستجابة الحركية & \\
\hline$\because .99$ & $\wedge$ & $1 . r 0$ & A.r & درجة & دقة اللمسة & \\
\hline
\end{tabular}

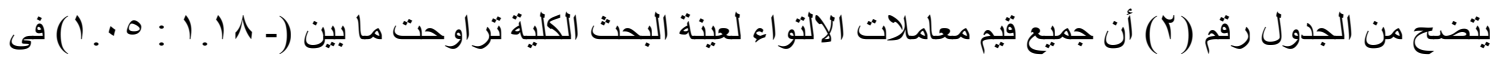

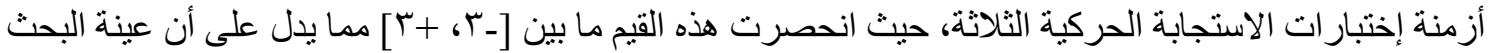
متجانسة ويمكن أن تكون نتائجها ممثله للمجتمع تمثيلاً اعتدالياً. وسائل و أدوات جمع البيانات:

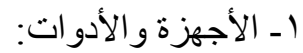

ميز ان طبى معاير لقياس الوزن لأقرب / / ـ كجم. - جهاز مقياس الطول رستامبر لقياس الطول لأقرب سم. - ساعة إيقاف لقياس الزمن مقدرً بالثانية حتى // . . 1 ثانية. 


$$
\text { - - استمارة تسجيل بيانات أفراد العبنه. }
$$

- كاميرا تصوير ماركة Fastec imaging (م كادر/ثانية).

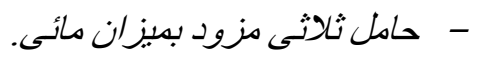
- مهاز Data show متصل بلاب توب محمل علية ملف خاص باسلوب تلدريب محاكاة تغيير العذف. - شاشة عرض بيضاء لا بقل العرض عن •0 اسم.

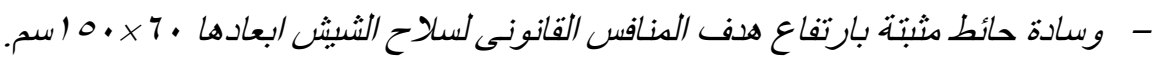
- ملعب سلاح شيث. - ملاح شيث. - -

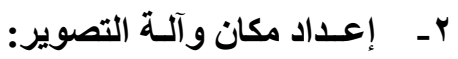

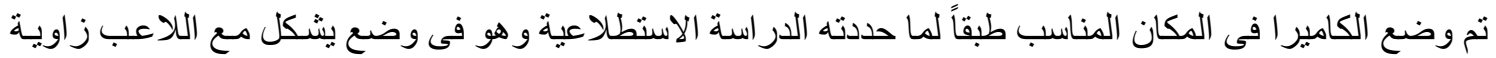

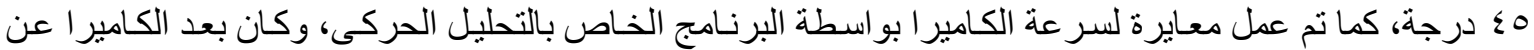

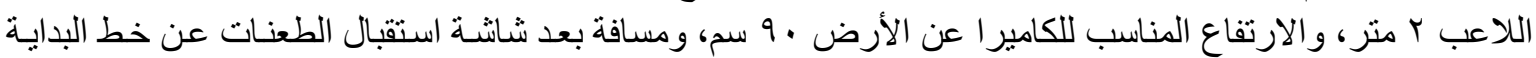

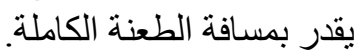

\section{r- م قياس المتغيرات الخاصة بزمن الاستجابة الحركية المركبة الانتقائية المقترنة بدقة اللمسات:}

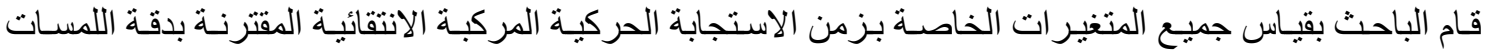

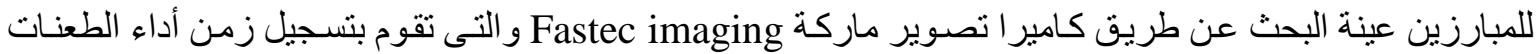

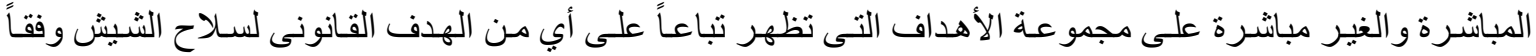

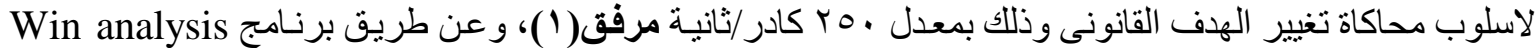

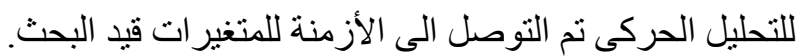

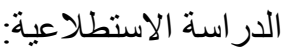

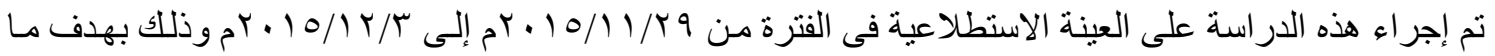

$$
\text { - تحديد المكان المناسب لوضع الكامير ا. }
$$
ـ تجهيز المكان المناسب لتفعيل اسلوب المحاكاة لتطبيق التدريبات و القياسات. ـ تحديد مدى ملائمة التندريبات و أزمنتها وفترات الراحة البينية لمستوى المبارزين. ـ مناسبة تكر ار ات كل تمرين داخل الوحدة التدرييية. وقد أسفرت نتائج الدر اسة عن تحديد الأدوات المناسبة للتدريبات و إجر اء بعض التبات التعديلات البسيطة فى التدريبات حتى تنتاسب مع المبارزين، كما أسفرت عن ملائمة المكان الخاص بالتطبيق.

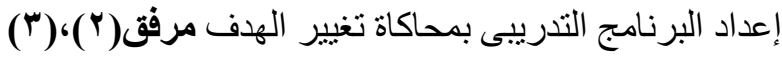

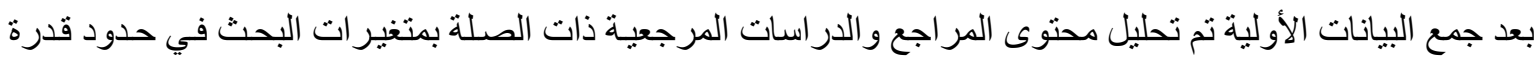

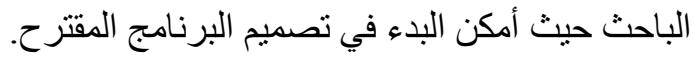

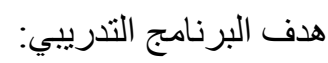


يهدف البرنامج التدريبى الى تحسين سر عة الاستجابة الحركية المركبة الإنتقائية و المقترنـة بدقة اللمسـات في المبارزة لدى عينة البحث التجريبية.

مدة البرنامج التدريبي: 1 أسابيع أسس ومعايير البرنامج التدريبي المقترح - أن يتناسب البرنامج التدريبي مع الأهداف الموضوعة وعينة البحث. - تحديد فترة تطبيق البرنامج التدريبي - مرونة البرنامج وقابليته للتعديل. - - تحديد زمن و عدد الوحدات التدريبية اليومية.

- تحديد شدة وحجم التدريبات وفتر ات الر احة البينية وفقاً للأحمال التدريبية ومحتوى وهدف كل مرحلة من مر احل فترة تطبيق البرنامج التدريبي.

\section{الأسس والمعايير الخاصة بتحسين زمن الاستجابة الحركية المركبة الإنتقائية}

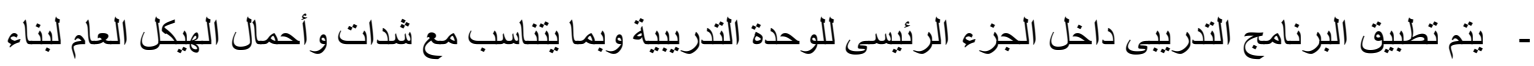

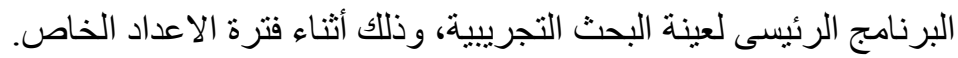
- يتم تطبيق البرنـامج على عينة البحث بإدخال المتغير التجريبي وهو تدريبات تغيير الهدف باسلوب المحاكاة في الجزء الرئيسي من الوحدة التدريبية.

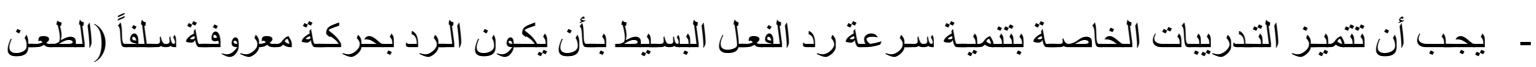
المباثر ) على مثير معروف سلفاً (العلامة الخضر اء على هدف المنافس) و التى تظهر بشكل مفاجئ.

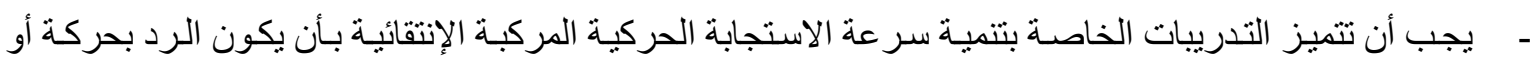

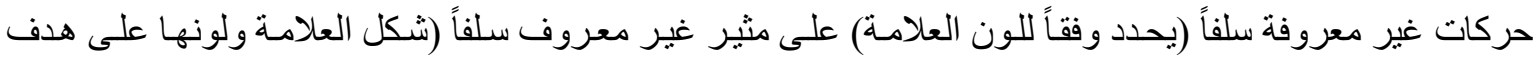
المنافس يغير الاستجابة الحركية) والتى تظهر بشكل مفاجئ.

- يجب أن تصل فترة الإحماء بقدرات الفرد الوظيفية للتهيئة المناسبة، وذلك تلافياً لخطر الإصابة والإجهاد.

$$
\text { محددات البرنامج التدريبي }
$$

- بعد تحديد هدف البحث وجد الباحث أنه يمكن تحقيق هذا الهدف مـن خلال تصميم مجموعة من التدريبات لتحسين

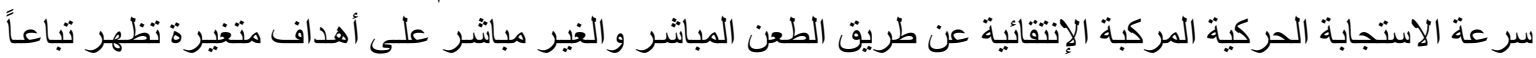

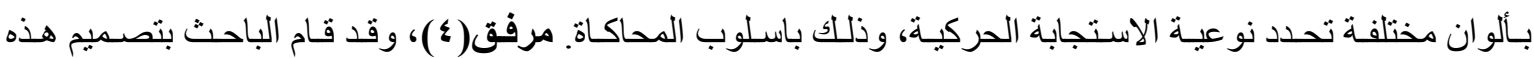

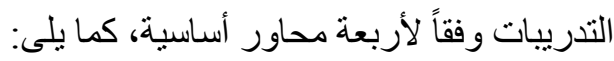
- المحور الأول: تدريبات لتنمية (سرعة رد الفعل البسيط). - المحور الثاني : تدريبات لتنمية (سر عة رد الفعل المركب باستجابة واحدة). - المحور الثالث: تدريبات لتنمية (سر عة الاستجابة الحركية المركبة الإنتقائية). - المحور الرابع: تدريبات لتنمية (سر عة الاستجابة الحركية المركبة الإنتقائية و الدقة على أهداف متحركة). وقد قام الباحث بتحديد البرنامج الزمني لتنفيذ هذه التدرييات بعد الإطلاع علي الدراسـات المرجعيـة خـلال فتره زمنيـة

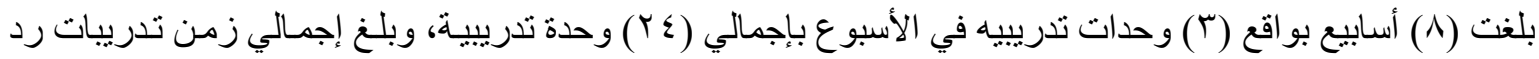




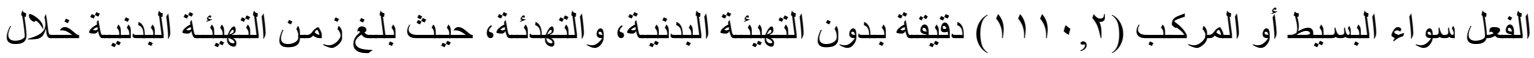

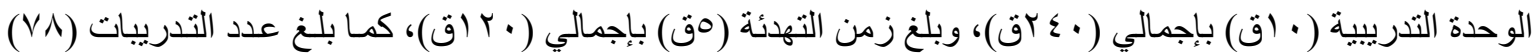

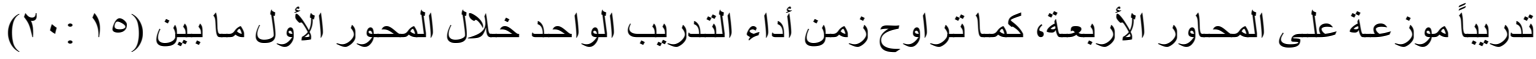

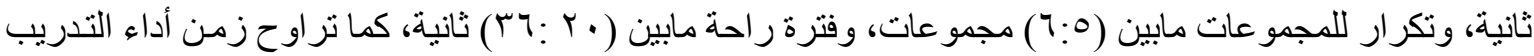

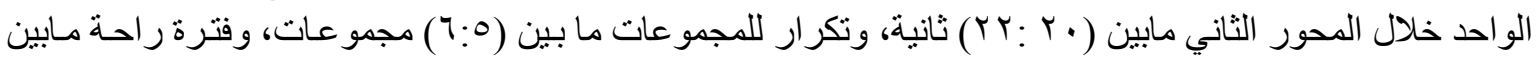

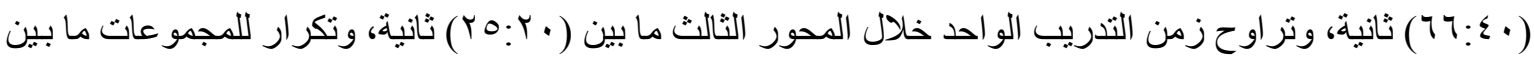

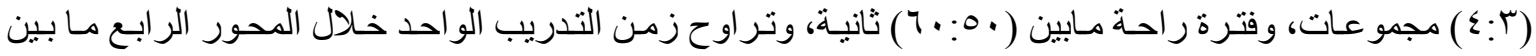

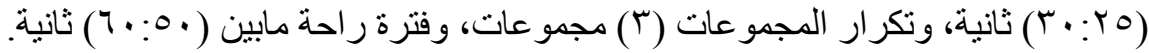

الار اسـة الأساسية:

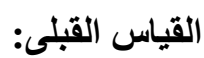

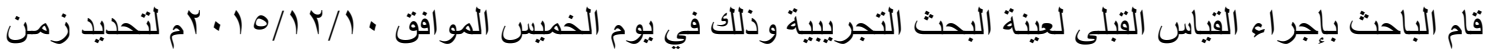

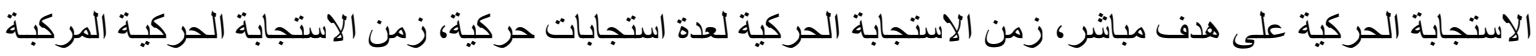
الإنتقائية و المقترنة بدقة اللمسات. تطبيق البرنامج التدريبى:

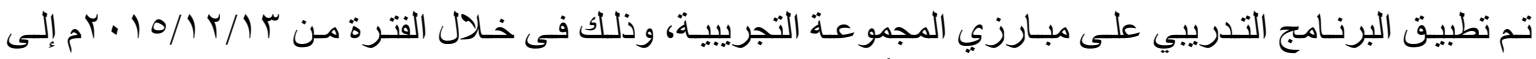

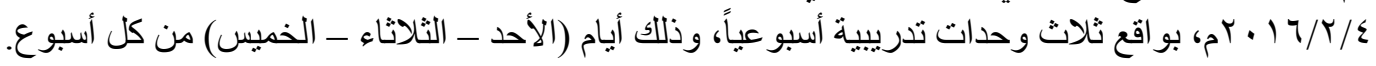
القياس البعدى: تم إجر اء القياس البعدى لأفر اد عينة البحث بنفس شروط ومو اصفات القياس القبلى بعد انتهاء مدة تطبيق البرنامج وذللك

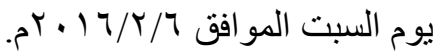

\section{المعالجات الإحصائية:}

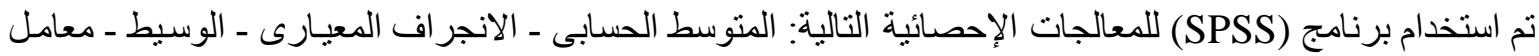

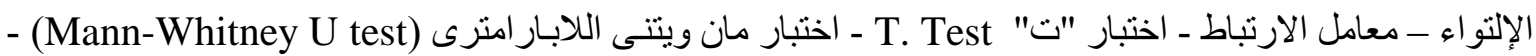
نسب التحسن. 


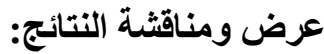

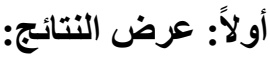

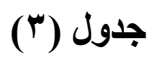

دلالة الفروق ونسب التحسن بين القياس القبلى والبعدى للمجموعة التجريبية في اختبارات زمن الاستجابة الحركية

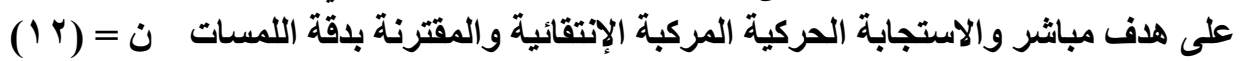

\begin{tabular}{|c|c|c|c|c|c|c|c|c|}
\hline \multirow{2}{*}{ 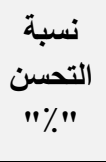 } & \multirow{2}{*}{ "تيمة } & \multicolumn{2}{|c|}{ القياس البعدى } & \multicolumn{2}{|c|}{ القياس القبلى } & \multirow{2}{*}{ والقياس } & \multirow{2}{*}{\multicolumn{2}{|c|}{ الاختبارات }} \\
\hline & & الالحيراف & الحسابي & الالانحراف & الحسابي & & & \\
\hline$\% 0.9 \leq$ & *Y.701 & Ir.1r & $\begin{array}{c}11 \leq \varepsilon . V \\
0\end{array}$ & $1 . . Y 4$ & $\begin{array}{c}199.5 \\
4\end{array}$ & ثانية & زمن رد الفعل & اختبار زمن \\
\hline$\% 1.99$ & "r.orr & $1 r_{\cdot} \cdot v$ & $\begin{array}{c}01 r .9 \\
r\end{array}$ & 0.01 & $\begin{array}{c}0 r \leqslant . r \\
r\end{array}$ & ثانية & زمن الحركة & الحركية على \\
\hline$\% .+7$ & *r.r & 11.99 & $\begin{array}{c}791.7 \\
V\end{array}$ & $9 . \cdot \varepsilon$ & $\begin{array}{c}V Y \cdot . V \\
0\end{array}$ & & زمن الاستجابة الحركية & هدف مباشر \\
\hline \% \% & "r.74 & $1 \cdot . r 4$ & $\begin{array}{c}r+1 . \varepsilon \\
r\end{array}$ & Ir.YE & $\begin{array}{c}\text { ro. } \\
1\end{array}$ & & زمن رد الفعل & اختبار زمن \\
\hline$\% 1 . \vee 7$ & $* \varepsilon .01 Y$ & Q.Ar & $\begin{array}{c}0 \wedge 4 . \\
\wedge\end{array}$ & A.VY & $\begin{array}{c}099.0 \\
1\end{array}$ & ثانية & زمن الحركة & الحركية لعدة \\
\hline$\%$ \%.q1 & * *.q ० & $1 \varepsilon . \cdot V$ & $\begin{array}{c}\wedge \vee .0 \\
.\end{array}$ & IV.TY & $\begin{array}{c}111.7 \\
V\end{array}$ & & زمن الاستجابة الحركية & استجابات \\
\hline$\% 0.1 \varepsilon$ & $* .9 \odot V$ & $1 \cdot .11$ & $\begin{array}{c}r \cdot Y . Y \\
0\end{array}$ & $11.1 \varepsilon$ & $\begin{array}{c}r Y V_{.} \\
r\end{array}$ & ثلانية & زمن رد الفعل & اختبار زمن \\
\hline$\% 1 . \vee r$ & *Y.roq & 11.00 & $\begin{array}{c}0 \wedge q_{.} \cdot \\
\wedge\end{array}$ & $1 r .09$ & $\begin{array}{c}099.8 \\
1\end{array}$ & ثلانية & زمن الحركة & الحركية المركبة \\
\hline \%.r.tr & $*$ *.$q \wedge r$ & Ir.1r & $\begin{array}{c}\text { vqo.r } \\
r\end{array}$ & $Y \cdot . \leqslant Y$ & $\begin{array}{c}\Lambda 18 . \Lambda \\
r\end{array}$ & ثلانية & زمن الاستجابة الحركية & المقترنة بدقة \\
\hline $\begin{array}{c}7 r . . \\
\%\end{array}$ & *q.rur & $1 . \cdot r$ & Ir.IV & $1.0 r$ & $\wedge . \cdot \wedge$ & درجة & دقة اللمسة & اللمسات \\
\hline
\end{tabular}

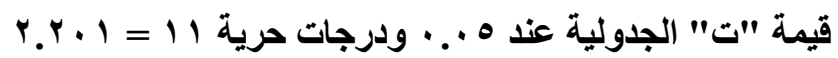

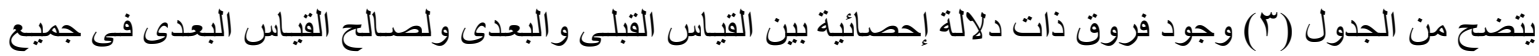

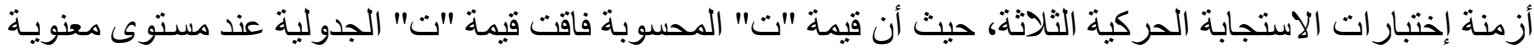

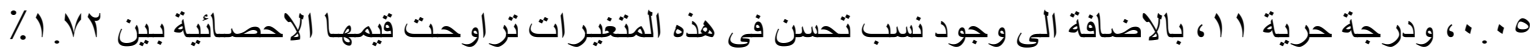




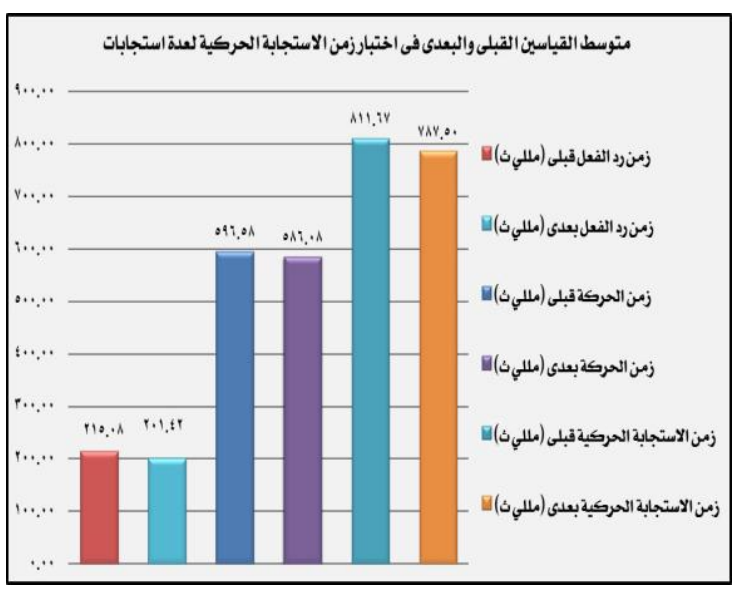

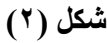

الفرق بين القياسين القبلى والبعدى فى زمن

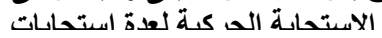

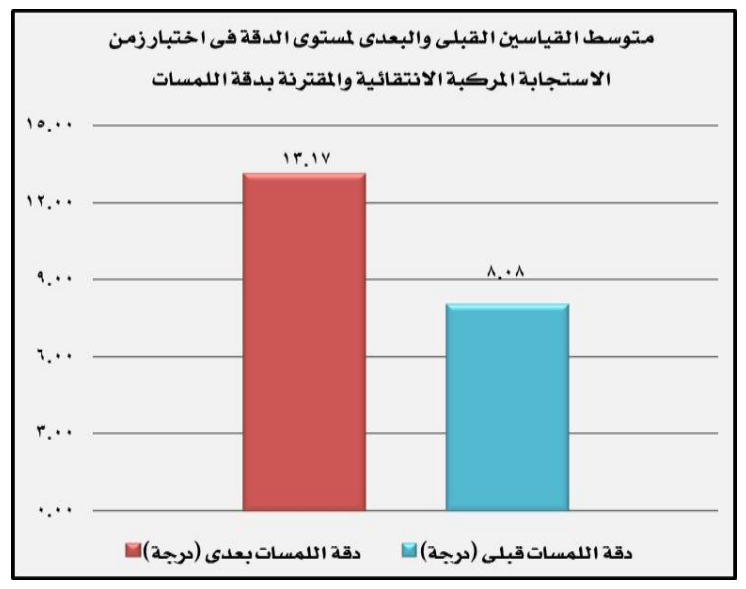

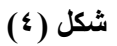

الفرق بين القياسين القبلى و البعدى فى مستوى الأبن اللقة لاختبار زمن الاستجابة الانتقائية والمقترنة بدقة اللمسات المات

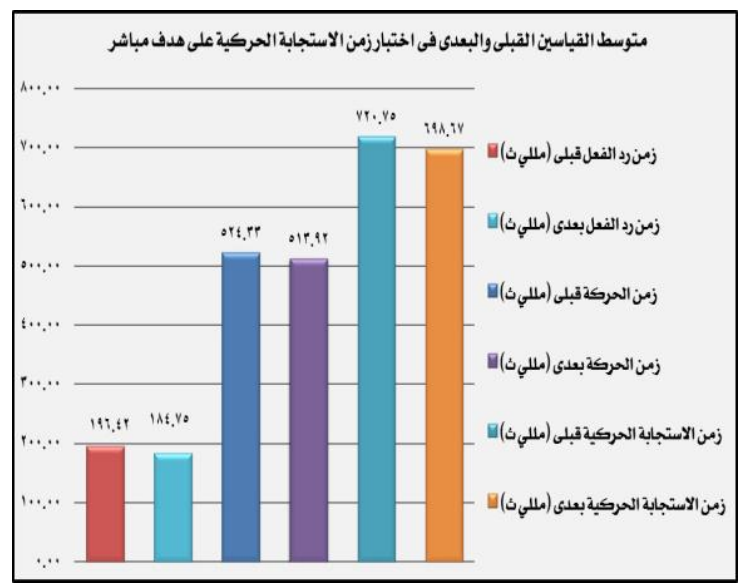

شكل (1) (1) (1)

الفرق بين القياسين القبلى و البعدى فى زمن

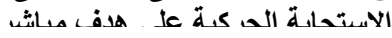

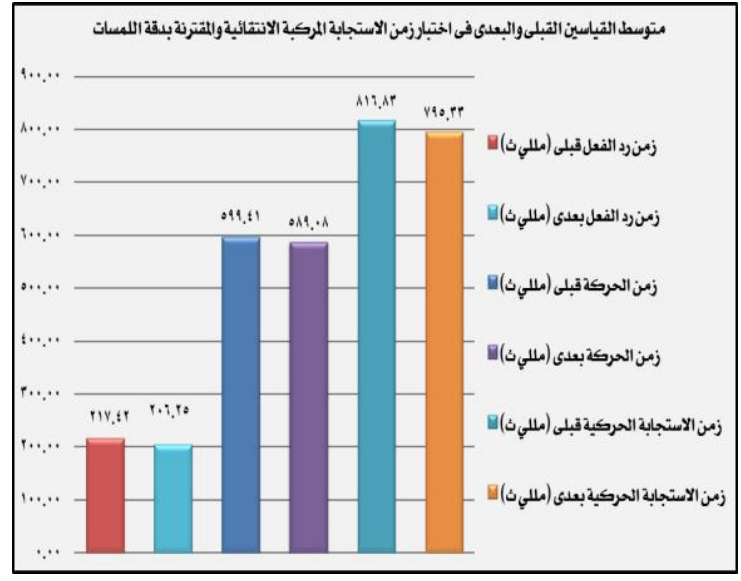

شكل (r)

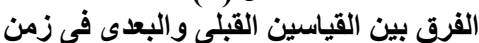

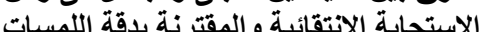


جدول (£)

مصفوفة معامل الارتباط بين متغيرات اختبار زمن الاستجابة الحركية المركبة الإنتقائية والمقترنة بدقة اللمسات

ir

\begin{tabular}{|c|c|c|c|c|}
\hline دقة اللمسات & زمن الاستجابة & زمن الحركة & زمن رد الفعل & \\
\hline & & & & زمن رد الفعل (مللى ثانية) \\
\hline & & & $\cdot 9 \cdot \varepsilon$ & زمن الحركة (مللى ثانية) \\
\hline & & $\because \wedge r \varepsilon$ & $\cdot$ •^צr & زمن الاستجابة الحركية (مللى ثانية) \\
\hline & $\cdot \Lambda \cdot r$ & . & $.9 \vee \wedge$ & دقة اللمسات (درجة) \\
\hline
\end{tabular}

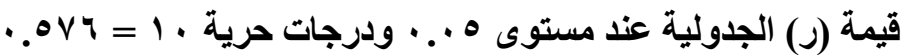

يتضح من الجدول (ع ) مصفوفة معامل الإرتبـاط بين متغير ات اختبـار زمن الاستجابة الحركية المركبة الإنتقائيسة و المقترنة بدقة اللمسات (زمن رد الفعل، زمن الحركة، زمن الاستجابة الحركية) ومستوى دقة اللمسـات على الهدف، الإن،

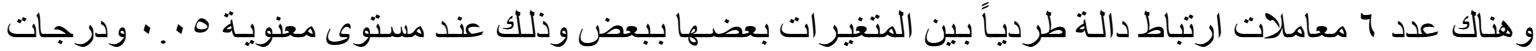

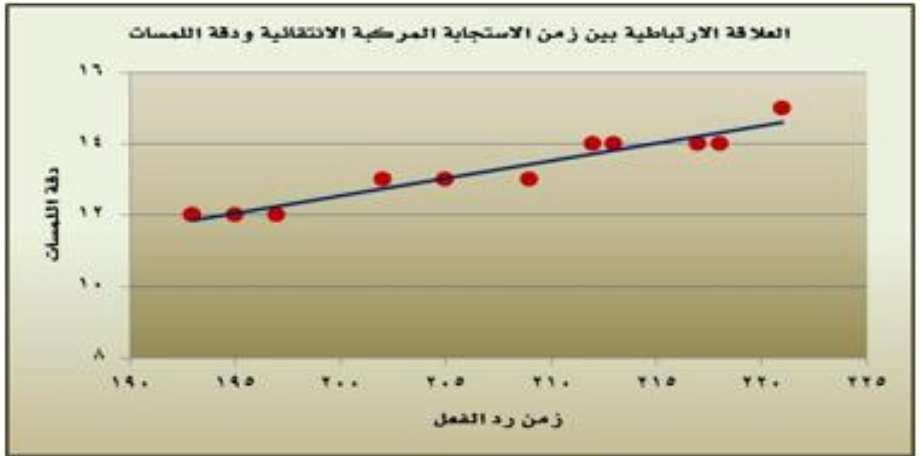

(5) (2)

معامل الارتياط يت زمن رد القمل ويقة اللمسات قي إختياز زمن الاستجاية الاحتقائية والمقترتة يدقة إنبمستات

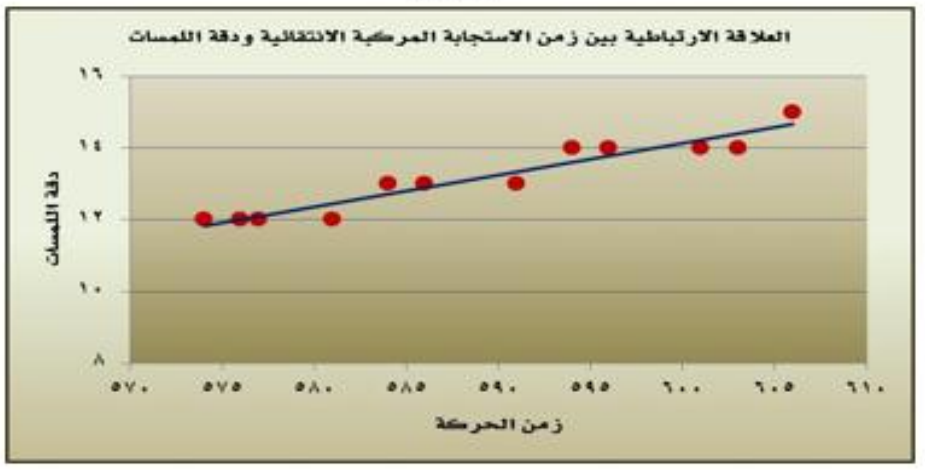

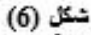

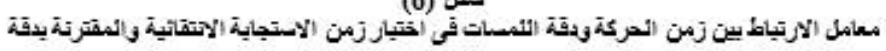
التمستات 


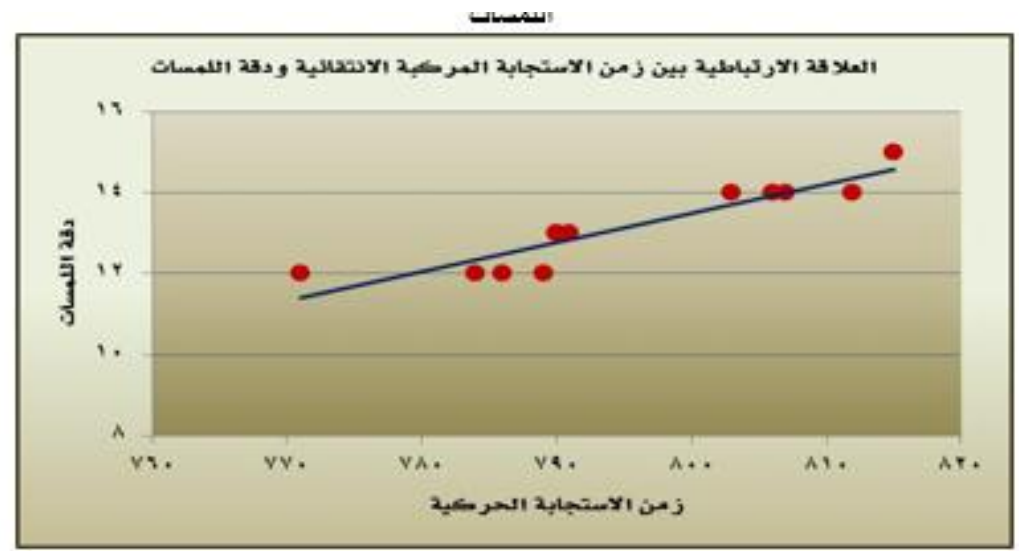

(7) شكت

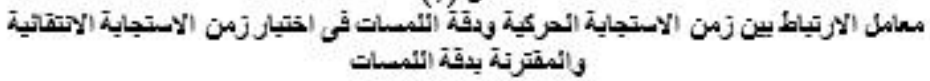

ثانياً: مناقشـة النتائسج:

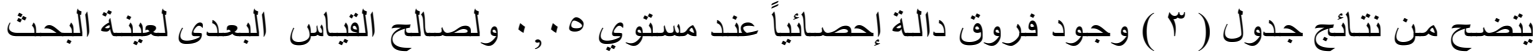

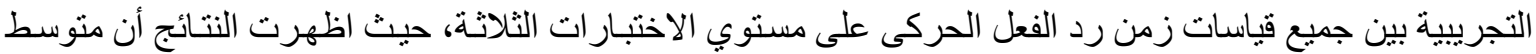

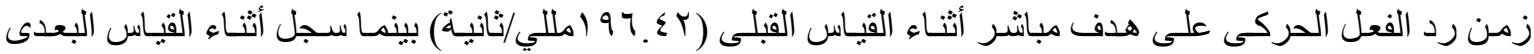

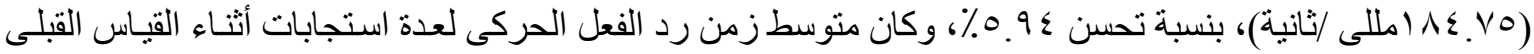

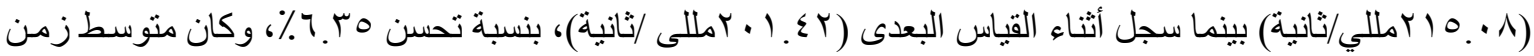

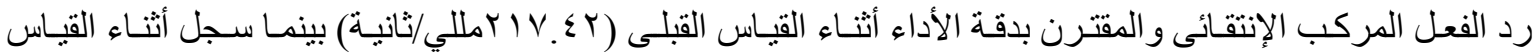

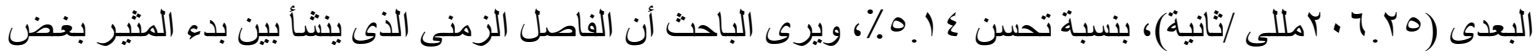

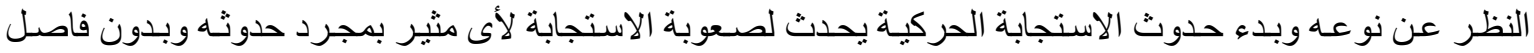

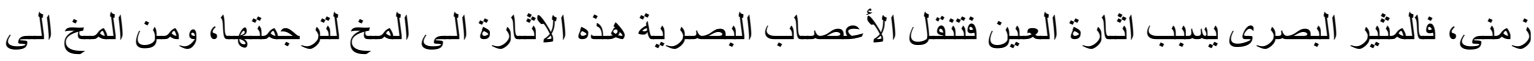

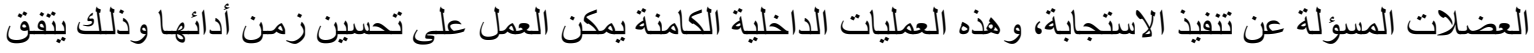

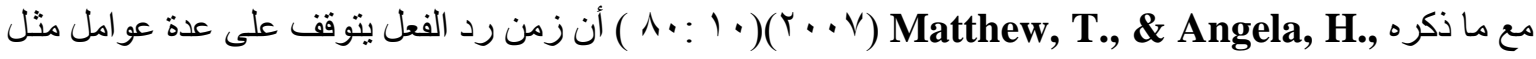

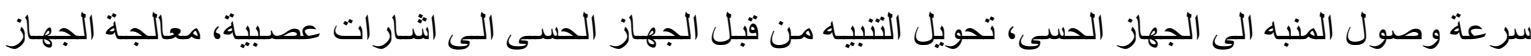

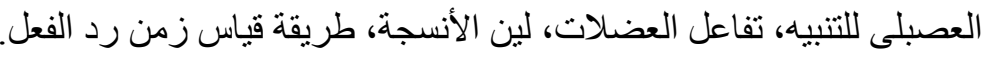

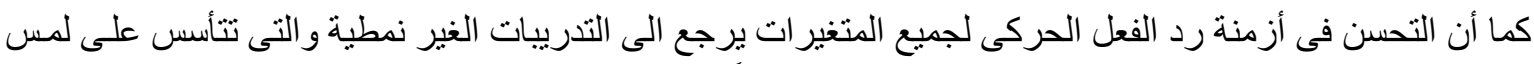

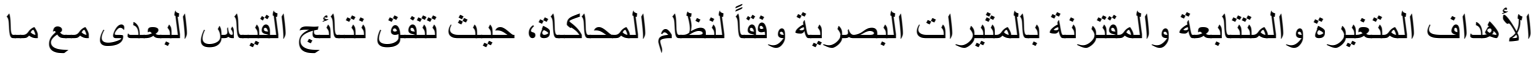

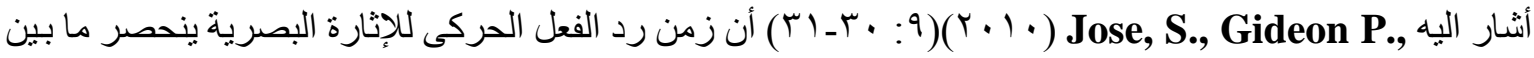

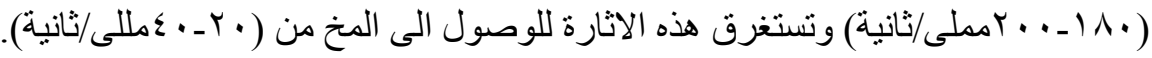

كما يوضح جدول ( r ) منوسط زمن رد الفحل وزمن الحركة وزمن الاستجابة الحركية خـالال ثلاثنة اختبار ات وكان

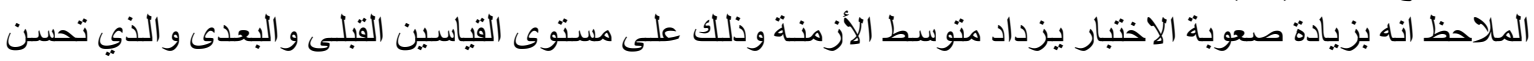

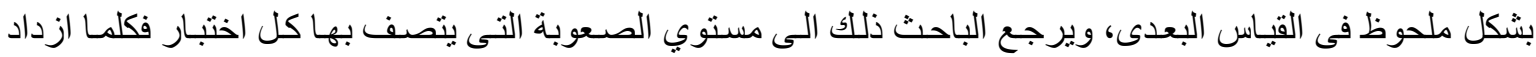

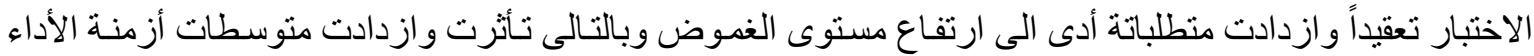

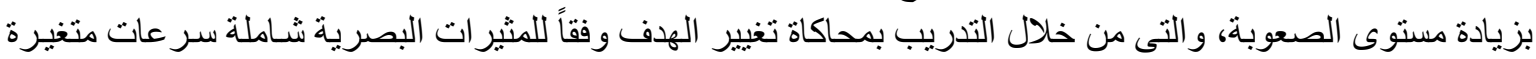
لأحداث غير متوقعة وتدريبات دقة على هدف محدد أدى الى تحسن متوسط الأزمنة خلال القياسين. 


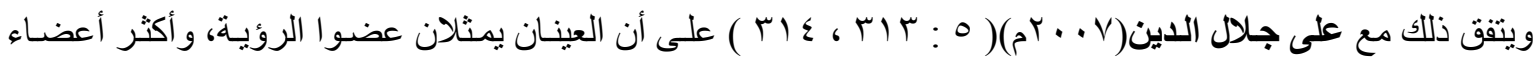

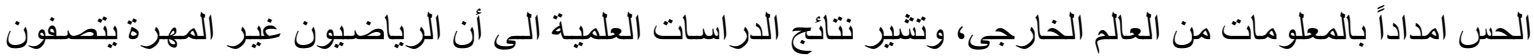

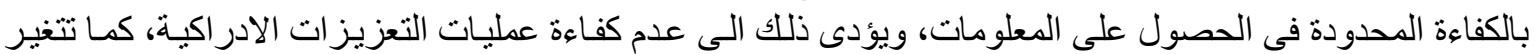

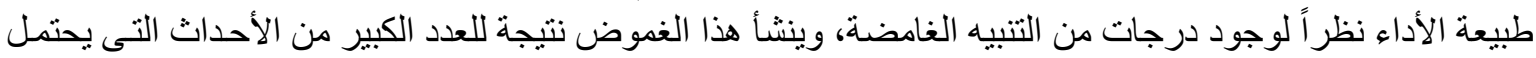

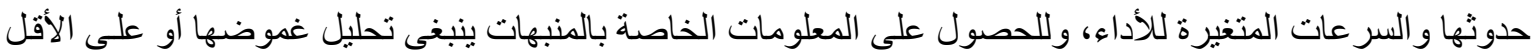

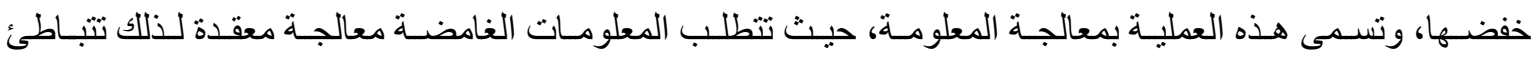
الاستجابات، بينما تتطلب المنبهات الواضحة معالجة أقل وتحدث الاستجابات لهذا النوع بصورة آلية.

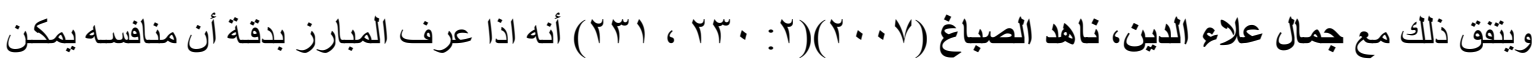

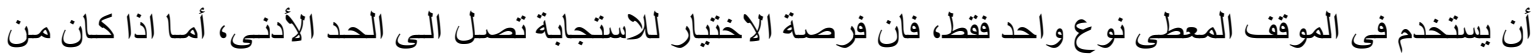

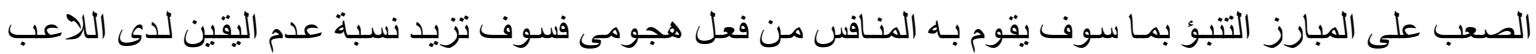
ويزداد زمن رد الفعل تبعاً لذللك.

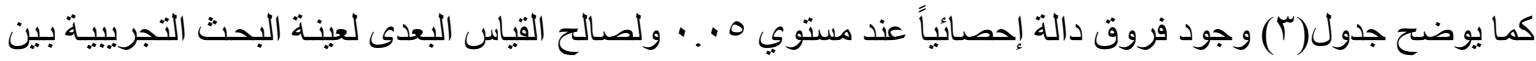

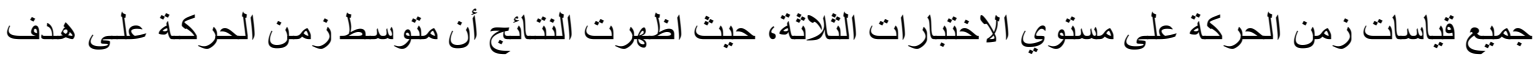

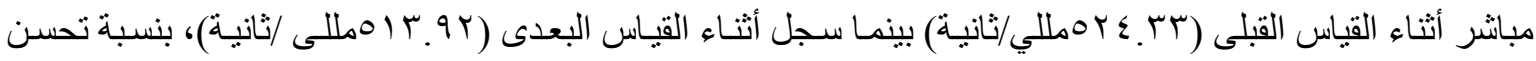

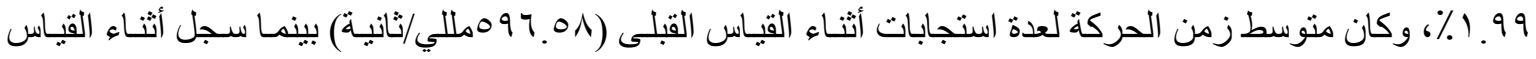

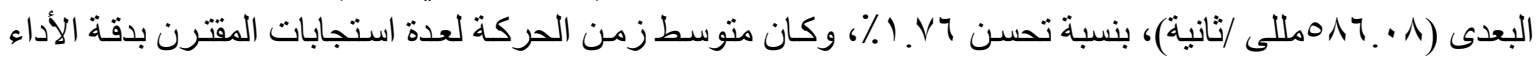

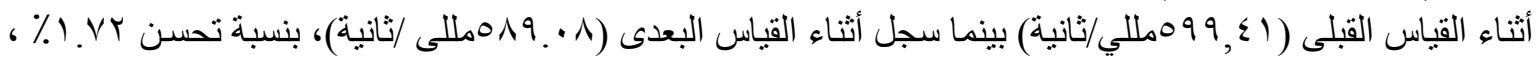

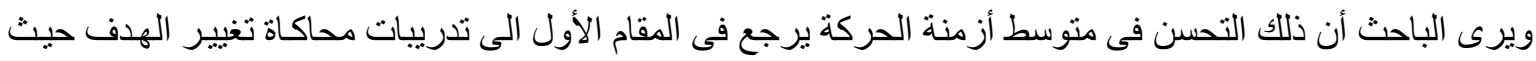

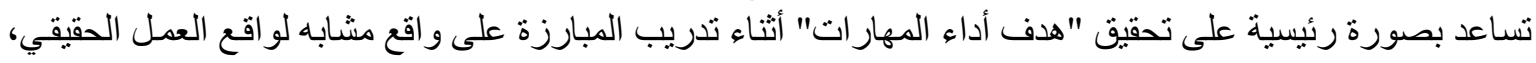

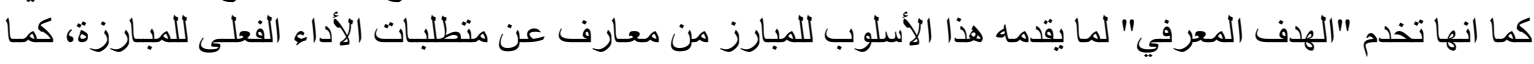

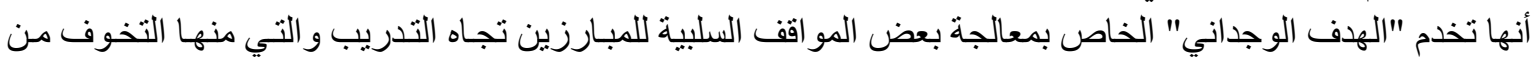

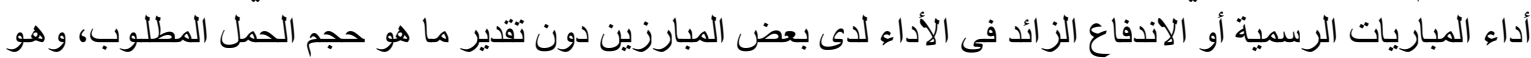

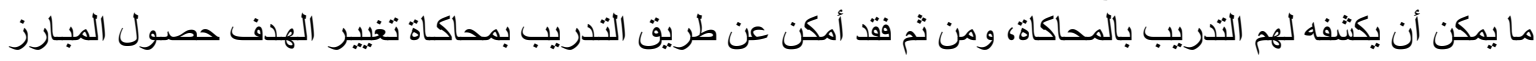

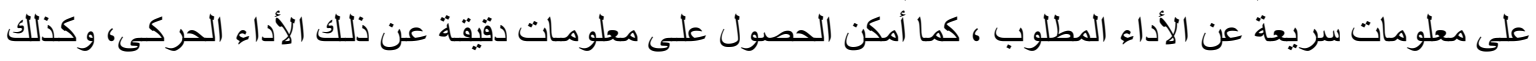

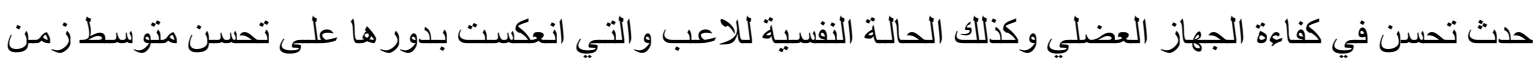

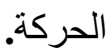

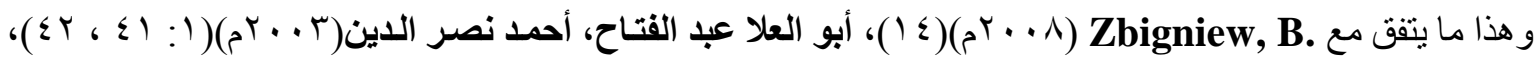

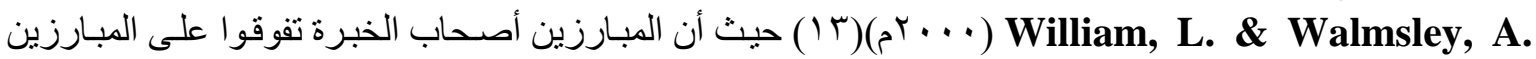

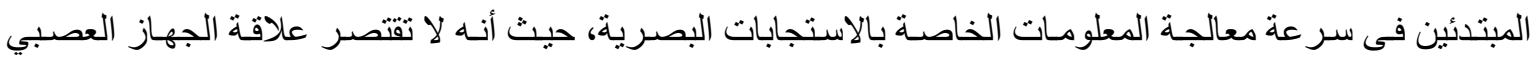

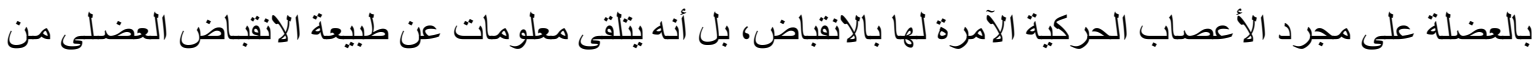

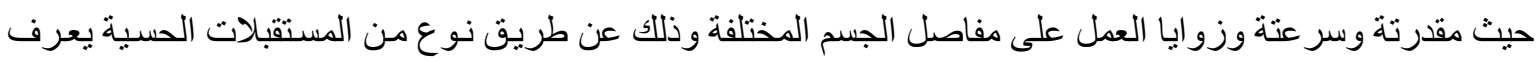

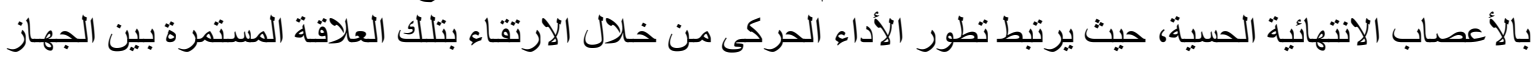

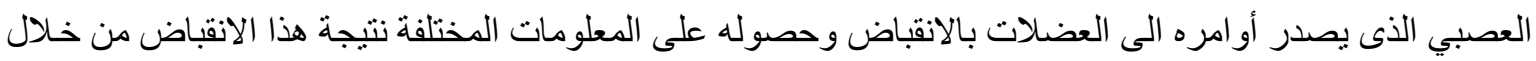

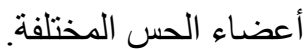

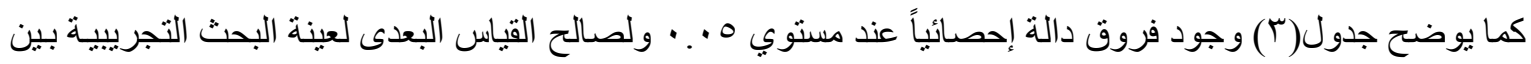

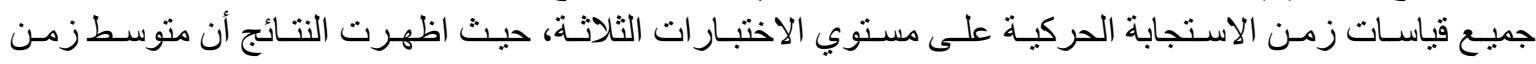

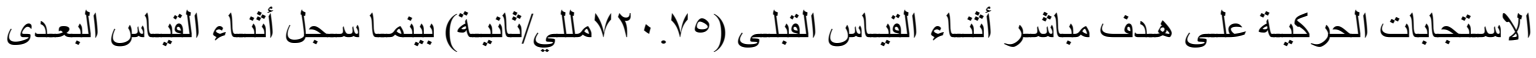

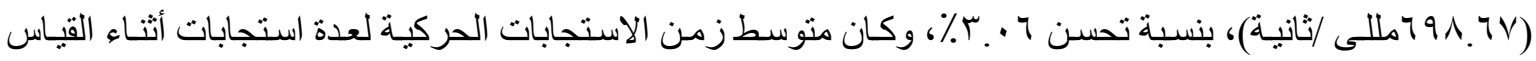




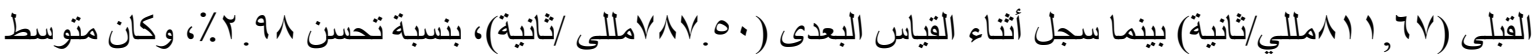

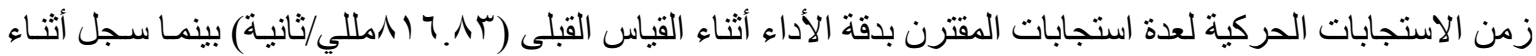

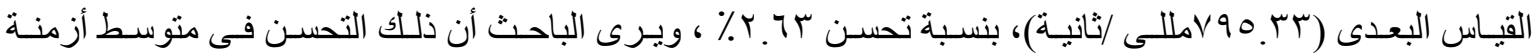

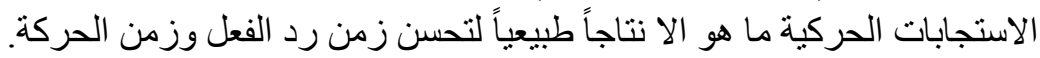

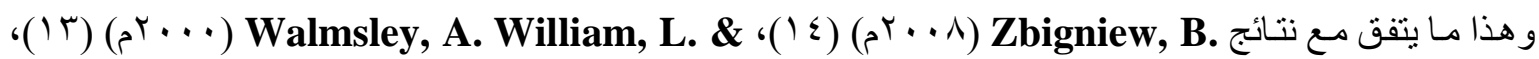
Sedondo, J. et al

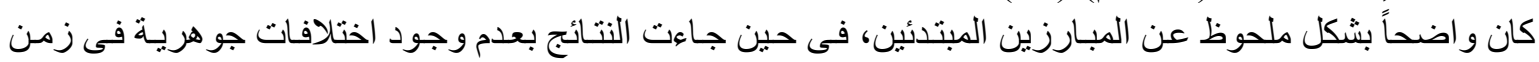
الحركة.

كما يوضح جدول(؟) وتحديداً بيانـات الاختبـار الثالث حيث يوضـح مدى التحسن الذى طر أ على مستوى الدقة أثنـاء

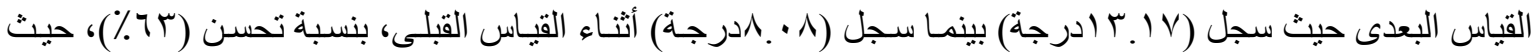

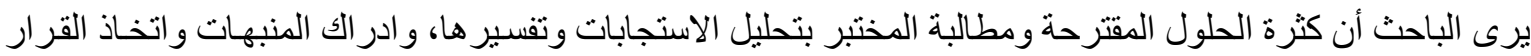

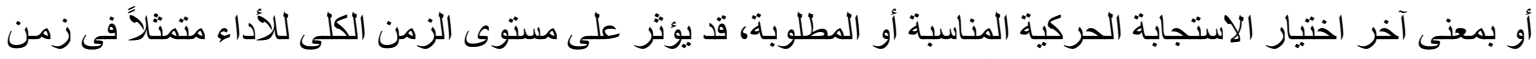

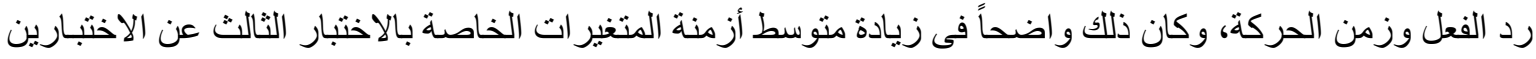

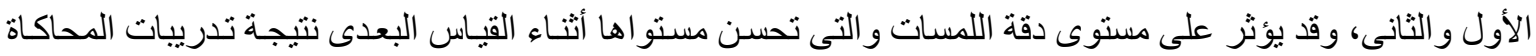

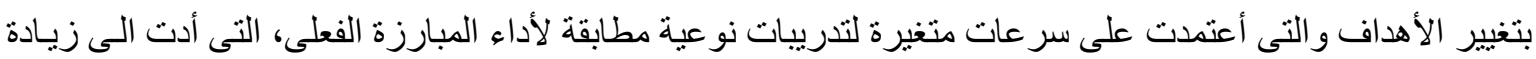

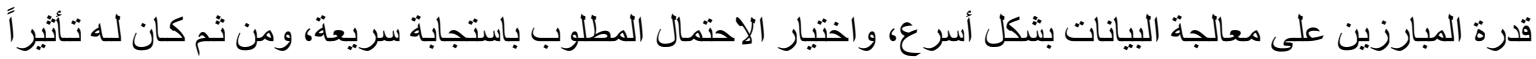

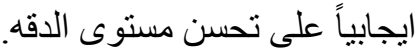

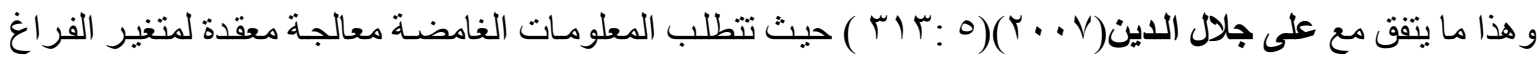

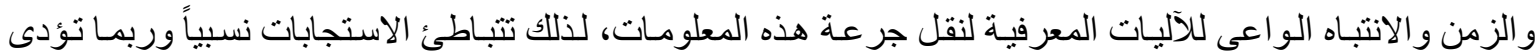
بمستوى أقل من الدقة.

كما يوضح جدول(ع ) مصفوفة معامل الإرتباط بين متغير ات اختبار زمن الاستجابة الحركية لعدة استجابات مقترن بدقة

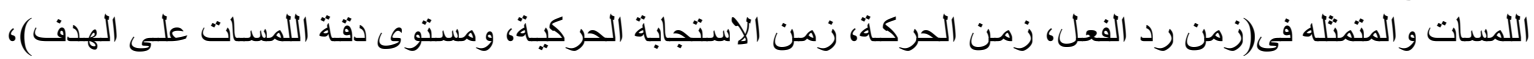

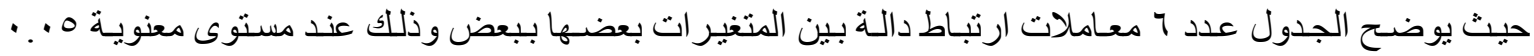

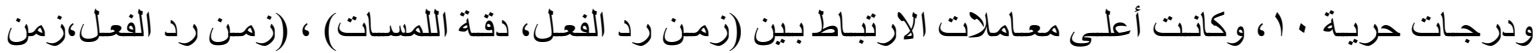

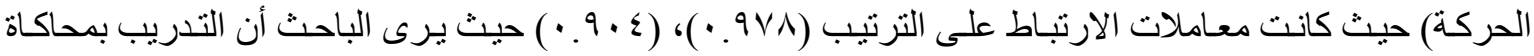

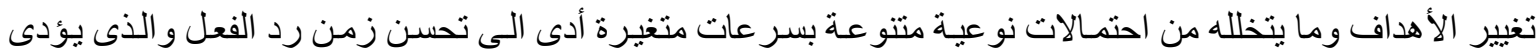

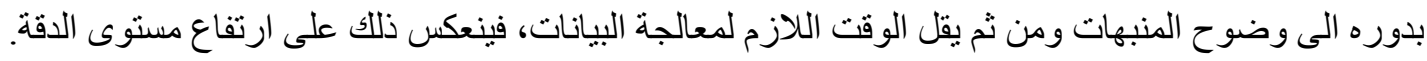

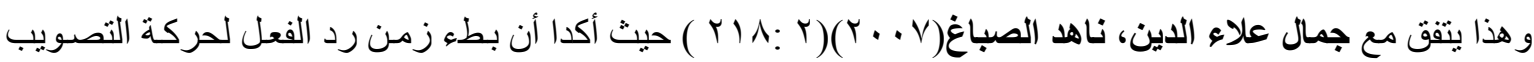

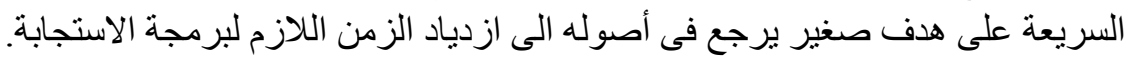

كما يرى الباحث أن الارتباط الطردى القوى بين زمن رد الفعل وزمن الحركة انمـا يرجع فى المقام الأول الى قصـر

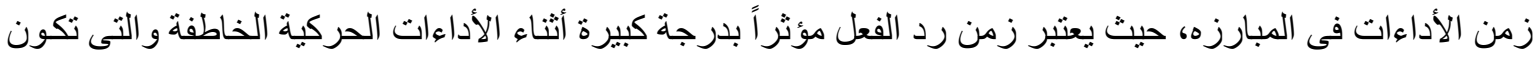

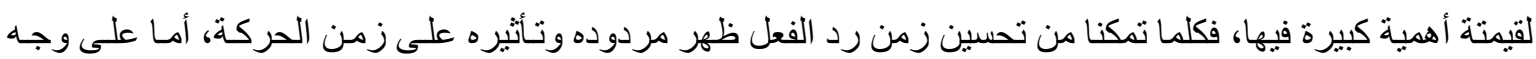

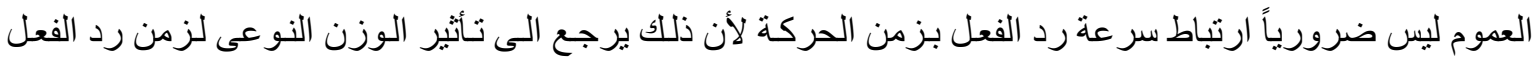
لجمل الأداء.

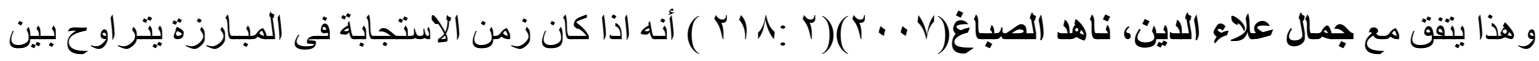

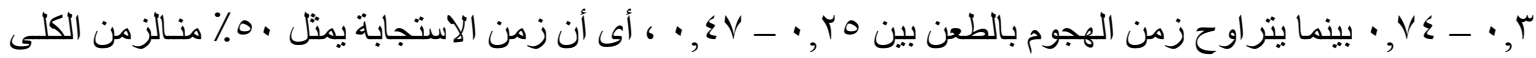

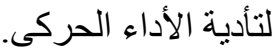




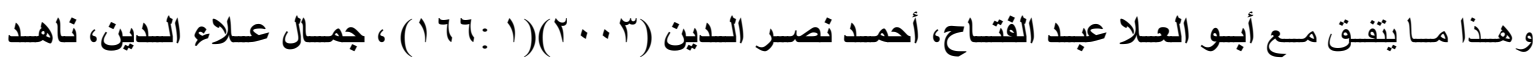

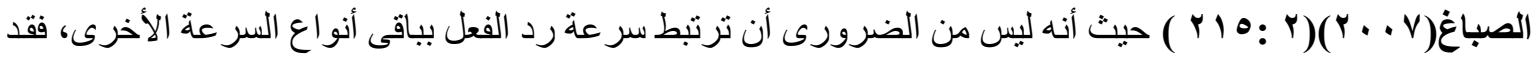

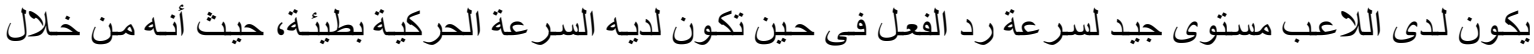

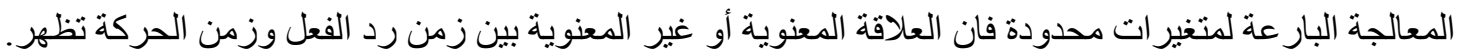

الاسـتنتاجات و التوصيـات أولاً: الاسـتنتاجات:

ا - استخدام اسلوب المحاكاة بتغيير الهدف كتدريب نوعى فى المبارزة قد يؤثر بالايجاب على مستوى الدافعيـة الذى الذى كان لله مردود ايجابى على متغير ات زمن الاستجابة الحركية المركبة الانتقائية. r- شدة المثير المتبعة فى تدريبات البرنامج كان عاملاً له تأثير على زمن رد الفعل وزمن الحركة. r- التدريب بمحاكاة تغيير الهدف ينتقل أثرها الى تحسن مستوى دقة اللمسة. ع- - تغيير الهدف وفقاً للاشار ات المنتظمة (الريتم المنتظم) يؤدى الى تحسن زمن رد الفعل. هـ ـ التدريب بمحاكاة تغيير الهدف يقلل من الزمن اللازم لبرمجة الاستجابة الحركية فيؤدى الى تحسن زمن رد الفعل الانتقائى على هدف من متعدد.

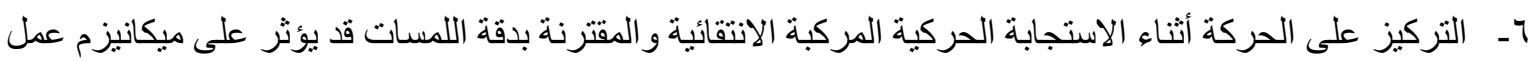
الذاكرة، مما يؤثر على زمن رد الفعل وزمن الحركة. V- ـ استخدام اسلوب المحاكاة بتغيير الهدف قد بؤثر على الفترة الزمنية الفاصلة بين المثير المحفز للاستجابة وبين الذى يسبقها مباشرة.

ثانياً: التوصيـات:

1 - ضرورة تطبيق أسلوب المحاكاة بتغيير الهدف ضمن بر امج الاعداد الخاص، قبل المنافسات.

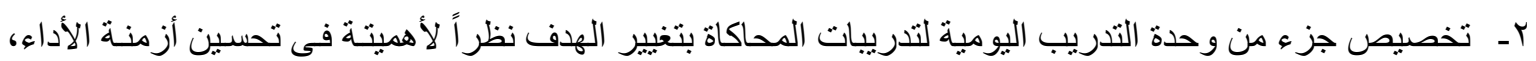
وكتدريب نوعى للأداء مقترناً بالدقة وفقاً للزئ الترن.

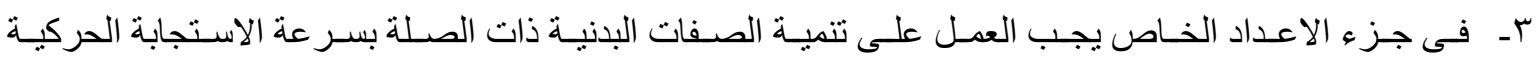

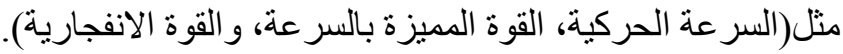
عـ العمل على تحسين سر عة الاستجابة الحركية الانتقائية تحت ظروف التعب وزيادة المجهود. 


\section{أولاً :المراجع العربية:}

1. أبو العلا أحمد عبد الفتاح، أحمد نصر الدين سيد (r . .rم): فسيولوجيا اللياقة البدنية، دار الفكر العربى، القاهرة.

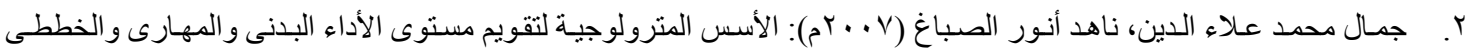
للإياضيين، منشأة المعارف، الاسكندرية.

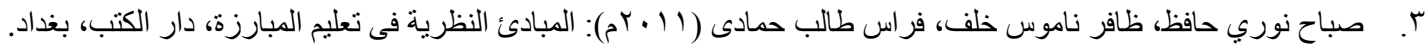

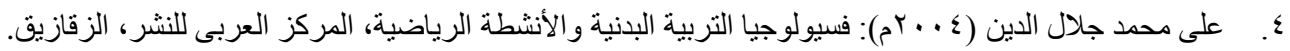

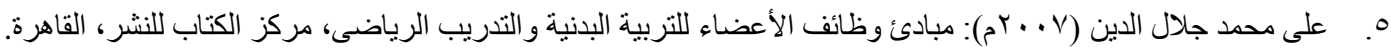
7. على محمد جلال الدين (• • (rم): فسيولوجيا التعلم الحركى، مركز الكتاب للنشر، القاهرة.

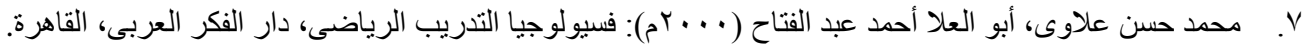
^. نعيم محمد فوزى (• ( • بم): التتبؤ بمستوى الأداء المهارى من خلال زمن وتكر ار الأداء وبعض المتغيرات الفسيولوجية للاعبى

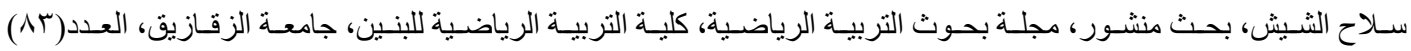

\section{ثانياً :المراجع الأجنبية:}

9. Jose, S., \& Gideon, P., (2010): Comparison between Auditory and Visual Simple Reaction Times, Neuroscience Medicine, 1, 30-32.

10. Matthew, T., \& Angela, H., (2007): Sprint starts and the minimum auditory reaction time, Journal of Sports Sciences, Vol. 25,No 1, PP 79-86.

11. Redondo, J., C.1; Alonso, C., J.1; Sedano, S., 2; de Benito, A., M.3 (2014): Effects of a 12-Week Strength Training Program on Experimented Fencers' Movement Time, Journal of Strength \& Conditioning Research, Vol 28 - Issue 12 - p 3375-3384

12. Richard, A., (1997): Continuous Concurrent Feedback Degrades Skill Learning: Implications for Training and Simulation, Human Factors and Ergonomics Society, 39(4), 509-525

13. Williams, L., \& Walmsley, A.,(2000): Response timing and muscular coordination in fencing: A comparison of elite and novice fencers, Journal of Science and Medicine in sport, Vol 3 - Issue 4 - $p$ $460-475$.

14. Zbigniew, B., (2008): The Significance of Sensorimotor Response Components and EMG signals depending on Stimuli type in Fencing, Faculty of Physical Education and Physiotherapy, Opole University of Technology, Opole, Poland, vol. 38, no. 1

15. http://kenanaonline.com/users/azazystudy/posts/131234. 